\title{
KAPITALISMIN KEHITYKSEN AIKAVYÖHYKKEISTÄ
}

tauksia löytyy erittäin harvoin. Tămä johtuu toisaalta siită, ettă arviomme "poliittisista mahdollisuuksista" ovat enemmän tai văhemmän epăvarmoja toisaalta siitå, ettă emme pysty asettamaan yksiselitteisiä tavoitteita. Voimme korkeintaan todeta, onko valittu strategia oikea vai ei. Useimmiten me voimme vain todeta, että se on oikeansuuntainen. Jos taas haluamme arvostella yksittäistă polittista tekoa, olemme jälleen samanlaisten ongelmien edessä. Yksittăistă poliittista tekoa voidaan nimittăin arvostella ainoastaan valitun kokonaisstrategian pohjalta ja koska tämä on aina luonteeltaan sangen "avoin", voimme vain păătyä siihen ettă kysymykseen, onko tietty poliittinen teko oikea vai văără, ei yleenså voida vastata ehdottoman kielteisesti tai ehdottoman myönteisesti.

Sakari Hänninen, Juha Pöyhönen ja Kaarlo Tuori kirjoittivat artikkelissaan Marxilaista lainoppia etsimässä (Tiede ja Edistys 2/ 1981), ettă minun käsitykseni tieteen ja ideologian vălísistä suhteista johtaa sühen, että "tieteellisen politiikan käsite joutuu romukoppaan" (s. 67). Olen tăssă yrittänyt selvittăä - itsellenikin - mikă kăsitykseni tieteellisestă politiikasta on. On toivottavasti tullut selvăksi, etten ole heittänyt tieteellisen politiikan kăsitettă yli laidan. Väitän vain, että meidän on oltava tietoisia tămän tieteellisyyden rajoista, sen paikasta politiikanteossa. Jos emme ole tietoisia tästă, syyllistymme helposti skientismiin, joka pahimmassa tapauksessa johtaa ehdottomaan ortodoksisuuteen ja poliittis-ideologiseen kykenemättömyyteen. Luulenkin, ettã erăs syy SKYP:n sisăisiin ongelmiin on siină, ettă liian monet toverit uskovat, ettă kaikkiin poliittisiin ja ideologisiin kysymyksiin on olemassa tieteellisesti păteviă, yksiselitteisiă vastauksia.

Lars D. Eriksson
Joachim Hirschin kiteyttămă kăsitys nyky-yhteiskunnan läpikapitalisoitumisesta on tärkeă. Epäilemättä ajatteluamme on vaivannut yksinkertainen kuva kapitalismin kehityksestă: tuossa kuvassa kapitalismi kasvaa esiin feodalismista lăhes täysikasvuisena aikuisena, jolla on edessäăn vain vanhuus, sairaat eläkelăispäivät ja kuolema. Kapitalismin elinvoimaisuus kuvasta on puuttunut.

Arto Noro on (Hirschiin viitaten) arvellut, ettă meidån ehkä pitäisikin năhdă kapitalismi tulemisensa prosessissa eikä luulla että jokin (Marxiin năhden) toisenlainen kapitalismi olisi syntynyt; nyky-yhteiskunta pikemminkin kapitalisoituu kuin on muuttumassa/mătănemăssä joksikin toiseksi, ja siksi Marxin ideat kapitalismista yleensä ovat vielä rautaa, toisin kuin mm. vamokap-teoria văittäă (Tiede ja edistys $1 / 81,49-50$ ).

Pekka Kosonen on tarttunut Noron heittămäăn kysymykseen. Myơs hăn pităă prosessitulkintaa tärkeänä, mutta vaatii sen pătevyysalueen tarkentamista. "Kiistassa 'kapitalismista yleensä' ja 'toisenlaisesta kapitalismista' en pidä kumpaakaan tulkintaa sellaisenaan hyvänä. On vălttămătơntä tarkentaa kysymyksenasettelua.... Kapitalismin historiassa on eroteltava erilaisia tasoja, jotka vaativat erityyppistă historiallisuuden tulkintaa. Päăomasuhteen etenemistä on syytä tarkastella kapitalisoitumisprosessina, joka asteittain laajenee eri yhteiskuntasuhteisiin. Tăllă tasolla kapitalismi on jatkuvasti tulemisensa prosessissa, ja olisi väärin puhua vain kapitalismin ylikypsymisestä. ... Toisella tasolla ovat ne suhteet, joita päăoma sellaisenaan ei voi alustaa. Valtiollistuminen esimerkiksi ei suoraan seuraa kapitalisoitumisesta. Se riippuu myös toimijoista, joiden toiminta ei redusoidu păăomasuhteen tai kapitalisoitumisen vaatimuksiin" (Tiede ja edistys 3/81).

Noro näyttäisi siis asettavan vastakkain käsitykset laadullisista muutoksista kapitalismissa ja yh- teiskunnan läpikapitalisoitumisesta. Kosonen kritikoi Hirschin valtiollistumisteesiä yksioikoisesta funktionalismista, mutta tuntuu hyväksyvän prosessitulkinnan pääomasuhteen etenemisen tasolla. Mielestäni prosessitulkintaa olisi kuitenkin tälläkin tasolla täsmennettävă, kuten Kosonen ohimennen viittaakin.

Palauttaisin ensin mieliin, että keskustelua "toisenlaisen kapitalismin" synnystä on meillä käyty ennenkin, mutta hieman eri yhteydessä. Keskustelu alkoi siitä kun useat "pääomaloogiset" marxistit BRD:ssä, Tanskassa jne. halusivat kiistăă monopoli- ja vamokap-teorian. Näită teorioita kritisoitiin sillä perusteella, että ne johtavat "Păăoman"' historioimiseen. Vir'heenă olisi tăllöin se, että "Päăomaa" pidettăisiin vain tietyn historiallisen vaiheen eli vapaan kilpailun kapitalismin kuvauksena, ja uutta vaihetta varten tarvittaisiin taas uusi vastaavan yleisyystason esitys. Kuitenkin "Päăoman" lait koskevat kapitalismia yleisesti eivătkă rajoitu sen tiettyyn vaiheeseen. Tämăn vuoksi on virheellistả puhua kapitalismin eri vaiheista, joista kullakin olisi omat lakinsa. Johtopäătöksenă on, ettă ei voida puhua yleisesti tendenssistă vapaan kilpailun kumoamiseen eikä ylipăănsäkăăn kapitalismin kehityksen jakamisesta tiettyihin vaiheisiin (ks. Kosonen 1981, 38-39 ja Kosonen ym. 1979, 70-75).

Pekka Kosonen ratkaisi tămän ns. historisiteettiongelman (kapitalismin jatkokehityksen käsitteellistämisen ongelman) täsmentämällä, että kapitalismin kehityksen vaiheistuksessa on kysymys kapitalismin sisäisten lakien toteutumismuotojen muutoksista. Vaikka kapitalismin sisäiset lait ovat luonteeltaan yleisiä, niiden toteutumismuodot muuttuvat historiallisesti. Näiden uusien toteutumismuotojen syntyă voidaan tarkastella kapitalismin "kehityslakien" (kapitalistisen kasaantumisen yleinen laki ja voiton suhdeluvun laskutendenssin laki) toimintaan liittyvien ristirii- 
tojen kasvun kautta (Kosonen 1981, 39-40).

Kososen ratkaisu vaikuttaa perustellulta, ja otan sen tässă annettuna. Tässă yhteydessă on oikeastaan olennaista vain se, että historisiteetti-ongelmasta keskusteltaessa kapitalismin kehitystä tarkasteltiin suppeammasta năkőkulmasta kuin nykyisessă läpikapitalisoitumisesta käytăvăssä keskustelussa. Historisiteetti-keskustelussa pohdittiin kapitalismin ydinvyöhykkeen muutoksia. Kysymys ei ollut joidenkin yhteiskunnallisten suhteiden kapitalisoitumisesta (päăomasuhteen leviämisestä) vaan kapitalismin jo valtaamien suhteiden kehityksestă, tai paremminkin kapitalistisen arvonlisäys- ja tuotantomuodon historiallisista muutoksista (pääoman elimellisen kokoonpanon kohoamistendenssi, ekstensiivinen ja intensiivinen uusintamistyyppi, tieteellis-tekninen kumous, päăomien keskittyminen ja yhteenkokoontuminen, voiton suhdeluvun laskutendenssi, monopolisoituminen, valtion taloudellisen intervention lisäăntyminen jne.).

Lăpikapitalisoitumisesta käydyssä keskustelussa on taas kiinnitetty päăhuomio päăomasuhteen leviämiseen. Kysymys ei ole vain alueellisesta leviămisestă (maailmanmarkkinat), tai kaikkien taloudellisten suhteiden kapitalisoitumisesta (palkkatyőläistyminen jne.) vaan lisäksi myös 'esikapitalististen' elämänmuotojen ja sosiaalisten suhteiden purkautumisesta (pakollinen liikkuvuus, sosiaalisten suhteiden tavaramuotoisuus jne.). Kysymys ei siis ole ollut kapitalismin ydinvyöhykkeestă vaan yhteiskunnan ulommista renkaista. Tällainen ydin- ja reunavyöhykkeiden erottaminen on tietysti raju yksinkertaisuus, muttei ehkă hyödytön. Muutama esimerkki.

Työttomyys on nykyisin kaikissa kehittyneissä kapitalistisissa maissa saavuttanut ennătykselliset mittasuhteet. Mistä se johtuu? Traditionaalinen marxilainen tutkimus on kiinnittănyt păăhuomion kapitalismin ydinvyơhykkeessă tapahtunei- siin muutoksiin (pääoman elimellisen kokoonpanon kasvu, automaatio ja uusi tekniikka, rationalisointi-investointien osuuden kasvu, tuotannon kasvun hidastuminen jne.). Läpikapitalisoitumisajatus kehottaa sen sijaan kiinnittämäăn huomion toisaalle: palkkatyőlăistymiseen (kaupungistuminen, omatarvike- ja pientuotannon supistuminen, naisten tyőssäkäynnin lisăäntyminen jne.). Työttőmyyden selittămisessä molemmat năkökulmat ovat tietysti tarpeeen: yhteiskunnan läpikapitalisoituminen työntää uutta tyővoimaa kohti kapitalismin ydinvyőhykettă, joka samaanaikaan on saavuttanut kehitysvaiheen jossa sen työvoimatarpeen kasvu on lähes olematon.

Toinen esimerkki voisi olla nykykapitalismiin liittyvän valtiollistumistendenssin selittäminen. Traditionaalisessa tutkimuksessa valtiollistumistendenssi on johdettu kapitalismin ydinvyőhykkeessä tapahtuneista muutoksista (tuotannon yleisistă ehdoista huolehtiminen, valtion tuki voiton suhdeluvun korkealla pitämiseksi ja kansainvälisessä kilpailussa menestymiseksi, tutkimuksen ja tyővoiman koulutuksen rahoittaminen jne.). Hirsch puolestaan johtaa valtiollisen rakenteen läpilyőnnin tyővoiman uusintamisalueen voimistuneesta kapitalisoitumisesta, esi- ja ei-kapitalististen sosiaalisten ja taloudellisten rakenteiden hajoamisesta. "Turvavaltion" perustana on vălttămättömyys kompensoida näin syntyvăä desintegraatiota normalisoimalla yksilöitä porvarillisen yhteiskunnan suhteisiin valtiollisen sääntelyn, valvonnan ja kontrollin kautta. Lienee ilmeistă, etteivăt nămå selitykset sulje toisiaan pois vaan tăydentăvăt toisiaan (samalla kun valtiollistuminen saa Hirschillă laajemman ja kriittisemmăn yhteiskunnallisen merkityksen).

Trivaalia? Varsinainen sanottavani onkin vasta seuraavissa kahdessa huomautuksessa:

1. Onko lăpikapitalisoitumisesta käydyssä keskustelussa jăänyt ka- pitalismin ydinvyöhykkeen kehitys liian văhălle huomiolle? Tarkoitan sită, etteihän yhteiskunnan läpikapitalisoitumisessa ole kysymys jonkin muuttumattoman ydinvyöhykkeen paisumisesta tai vaikutuksista yhä laajemmalle, vaan nimenomaan muuttuvan ydinvöhykkeen vaikutuksista. Hirschillä ydinvyöhykkeen muutos on kylla koko jutun takana: "Keskeistă on lähteă siitä, ettei päăoma voi koskaan uusintaa itseăăn samanlaisina săilyvissä yhteiskunnallisissa olosuhteissa. Voiton suhdeluvun laskutendenssin paineen alaisena sen on jatkuvasti mullistettava yhteiskunnalliset olosuhteet. ... suhteellisen lisäarvon tuotannon dynamiikka on ratkaiseva kapitalistisen riistosuhteen săilymiselle. Tämă ei tarkoita vain tuotantovoimien jatkuvaa kehitystä (ydinvyöhyke - RL) vaan myös (ulommat vyöhykkeet - RL) syvällekäypäă yhteiskunnallisten rakenteiden vallankumouksellistamista kapitalistisen tuotantotavan sisällä." (Tiede ja edistys $1 / 81,36$ ). Vasta moderni kapitalistinen ydinvyöhyke tekee mahdolliseksi ja vălttămăttơmăksi yhteiskunnan läpikapitalisoituminen (vrt. esim. maailmanmarkkinoiden muodostuminen). Tămă ei tarkoita etteik $ठ$ teollistumisen alkuvaiheessa ydinvyöhykkeellä olisi ollut vaikutusta ulompiin vyöhykkeisiin, mutta tuo vaikutus ei ollut niin läpitunkeva ja rakentui osin esikapitalististen suhteiden varaan (vrt. 1800-luvun lopun työläisyhteisojjen muodostuminen ja niiden văhittăinen hajoaminen ydinvyöhykkeen muutoksen myötä).

2. Jos năin on, se merkitsee samalla sitä, että kapitalismin vyöhykkeet ovat eriaikaisia. Ydinvyöhykkeellă on ollut jo pitkă "kapitalistinen historiansa" kun kapitalisoituminen vasta alkaa voimakkaammin tapahtua ulommilla vyöhykkeillă. Ja siksi ei ole vălttămăttă ristiriitaista sanoa, ettă nykykapitalismi on yhtå aikaa ylikypsăă kapitalismia (ydinvyöhyke) ja kypsyvăă kapitalismia (yhteiskunnalliset suhteet koko laajuudessaan). Sa- 


\section{HONKASALON ENTROPIA- KRIISI}

maan aikaan kun kapitalismi on vasta tunkeutumassa joillekin elămănalueille, on ydinvyöhykkeessă havaittavissa pääomasuhteen hajoamistendenssejä. Monopolisoituminen ja valtiollistuminen voidaan toki năhdă tăstă perspektiivistă: "Niin pian kuin se (kapitalismi - RL) alkaa tuntea ja oivaltaa itsensä kehityksen rajaksi, se turvautuu muotoihin, jotka, vaikka ne năyttävătkin tekevän tăydelliseksi päăoman herruuden panemalla aisoihin vapaan kilpailun, ovat samalla păăoman hajalle laskemisen ja sille perustuvan tuotantotavan hajalle laskemisen julistusta" (Marx, Grundrisse, 544-545). Puu voi kasvaa leveyttă ja pituuttakin vaikka sen ydin on jo lahoamassa. Toki ydinkäăn ei ole läpeensă mătă (dogmaattisen marxilaisuuden kanta) eikä automaattisesti muuttumassa văhemmän kapitalistiseksi (sosiaalidemokraattinen kanta), mutta silti: kapitalismi on nykyisin sekă tulossa että menossa yhtäaikaa.

Hirschin ansio ei mielestăni olekaan siinä, ettă hän osoittaisi meille Marxin käsitysten kapitalismista yleensä olevan vielä rautaa (sehän on ollut selvăă jo pitemmän aikaa?), vaan siinä ettă hän osoittaa rikkaasti kapitalismin ydinvyobhykkeessă tapahtuneiden modifikaatioiden seuraukset tyővoiman uusintamiselle, poliittiselle rakenteelle jne. Samalla kapitalismin historiallinen aika paljastuu monikerroksiseksi, seikka jota erityisesti Sakari Hänninen on korostanut. Ja näin hăn tarkentaa kuvaamme nykykapitalismista (siitä "toisenlaisesta kapitalismista").

Tässă ovat hiukset ja halko, hyppäă siită!

Raimo Lovio
Antero Honkasalo kirjoittaa Tiede ja edistyksen numerossa 1/1981 termodynamiikan entropia-kăsitteestă ja sen alkuperăistä käyttöalaa laajemmista merkityksistă ("Raaka-aine ja ympäristőongelmat - entropiakriisi?"'). Mielestäni Antero Honkasalon tapa kăsitellä aihettaan vähintäänkin johtaa văärinkăsityksiin, ellei perăti ole ilmausta tiedostamattomasta fysikalismista ja mystismistä.

Puutun ensiksi erääseen pikkuseikkaan Honkasalon kirjoituksessa. Hänen mukaansa termodynamiikan toinen pääsääntö on "ns. empiirinen laki" (s. 19). Mikäli näin olisi, olettaisi jatkuvasti tehtävän kokemusperäistă tutkimustyớtä (kokeita ja havaintoja) siită, pitääkő termodynamiikan toinen pääsäăntő paikkaansa. Siis esimerkiksi yritettăisiin rakentaa energeettistă ikiliikkujaa!

Aineellisia järjestelmiă koskevana laki entropian kasvamisesta suljetussa järjestelmässä on raudanluja. Havainto siitä, ettei näin tapahtuisi, romuttaisi koko maailmankatsomuksemme. Koko fysiikka jouduttaisiin rakentamaan uudestaan, aineksista, joita emme osaa alkuunkaan kuvitella (liekő sellaisesta maailmasta edes science fictiota kirjoitettu).

Sen sijaan tapaamme päivittäin ilmiöitä, joiden yhteydessä järjestelmän entropia vähenee, vaikka mikă tahansa fysikaalinen malli sille edellyttäisi entropian kasvua. Esimerkiksi sekavat ajatuksemme saattavat järjestyä oivallukseksi ilman että niihin ulkoapäin tuotaisiin "uutta" pelkästään sisäisellä dynamiikallaan. Vastaavasti yritys kuolemalla ja hävityksellä (entropian lisäämistä) tukkia El Salvadorin kansan tie kohti uutta, aikaisempaa korkeampaa (vähäisemmän entropian) yhteiskuntajärjestelmää ei tule onnistumaan.

Entropiasta puhuttaessa pitäisi joka tapauksessa ehdottomasti vălttäă seuraavanlaisia ilmaisuja: "'Biosfääri. . . käyttää hyväkseen auringon matalan entropian varastojen huipentumista" (s. 20). Po:
"Biosfäri saa energiansa auringolta, samalla aurinko-systeemin entropia kuitenkin kasvaa ikäänkuin biosfăări kăyttăisi hyvăksi auringon matalan entropian "varastoa".

Tai: "Aineen kiertokulut ovat lisäksi siinä määrin suljettuja, ettei elämän ympäristőoonsä syöttämä korkean entropian virta koostu juuri muusta kuin lämpösäteilystă ...". Po: "Elollisessa luonnossa aine kiertäă ja käytetään uudelleen hyväksi. Tämä järjestelmä menettääkin vain energiaa ikäänkuin "korkea entropia" virtaisi lämpösäteilynä tai sen mukana avaruuteen."

Puhe entropian virtaamisesta on mielestäni äärimmäisen harhaanjohtavaa paitsi silloin, kun järjestelmän sisällä epäjärjestys siirtyy - vaikkapa kun jonossa joku tőytăisee jonon hännillä. Häiriö etenee samalla kun häntäpäă korjaa tilanteen - entropia virtaa!

Mikäli Honkasalon tavoin puhutaan entropian virtaamisesta on tietenkin yhtä lailla luontevaa puhua entropiavarastoista ikäänkuin sitä jonnekin padottaisiin (s. 20-21): Tehtäväkohtaista ". . .tehokkuutta kutsutaan nimellä second law efficiency, koska se mittaa sitä matalan entropian varastojen minimikulutusta, jolla tehtävä pystytään suorittamaan. Tämän 'entropisen tehokkuuden' arvot ovat tavallisesti pienempiä kuin energeettisen tehokkuuden arvot. ... on arvioitu olevan. . . teollisuudessa $\ldots 0,25$ ja liikenteessä $0,1 . "$

Maantieteilijän pohjakoulutuksellani yritän arvata mitä Honkasalon entropinen tehokkuus tarkoittaa: "Tehtäväkohtainen tehokkuus on tehtävään kuluvan teoreettisen minimienergian suhde todella kulutettuun (tuhlattuun ja välttämättömään) energiamäärăän. Esimerkiksi autoliikenteessä kuluu energiaa kymmenkertaisesti se määrä, mikă on teoreettinne minimi. Tällöin on mukana bensan lisäksi se energia, mikä tarvitaan autojen valmistamiseen ja huoltoon, 